\title{
La Biblioteca Digital del Patrimonio Histórico: hacia la integración de los recursos especializados en el ámbito patrimonial
}

\author{
Nieves González Fernández-Villavicencio \\ Biblioteca Universitaria de Sevilla \\ Isabel Ortega Vaquero \\ Centro de Documentación del Instituto \\ Andaluz del Patrimonio Histórico
}

La irrupción y socialización de Internet ha provocado cambios importantes en las bibliotecas, por la aplicación de la tecnología de la información y las comunicaciones (TIC). La infraestructura tecnológica adecuada produce un modelo de biblioteca que ofrece al usuario más cantidad de información relevante, exacta y confiable, con "acceso fácil e inmediato a la información" (Digital Libraries. IFLA), esto es, la Biblioteca Digital.

Existe una gran confusión respecto al concepto de biblioteca digital y se han usado diferentes términos para definirla: biblioteca virtual, biblioteca digitalizada, biblioteca electrónica, biblioteca sin paredes y, más recientemente, biblioteca digital. Hay una cierta indefinición ya que el término resulta atractivo, pero no se sabe bien qué es ni qué posibilidades puede ofrecer.

La biblioteca digital se concibe a partir del uso intensivo de las TIC en su diseño y formas de servicio. No se trata únicamente de cambiar la forma y maneras de difundir los documentos, sino de ensayar nuevas formas de preservar, organizar y difundir el conocimiento por medio de colecciones de documentos digitales. Se nos demanda que ofrezcamos una biblioteca basada en las nuevas tecnologías, con un acceso automático fácil e inmediato a los recursos de información, bases de datos bibliográficas y documentales, y documentos en texto completo (documentos primarios), desde cualquier parte del mundo y por cualquiera (The University of California Digital Library).

De acuerdo con el concepto, características y elementos constitutivos de la Biblioteca Digital, se plantea una propuesta para la creación y desarrollo de la Biblioteca Digital del Patrimonio Histórico.

\section{CONCEPTOS BÁSICOS}

\section{I.I. Introducción}

Estamos en un periodo de cambio en nuestra sociedad. Todos somos conscientes de ello. La irrupción de los ordenadores en nuestras vidas está cambiando para bien o para mal, el propio concepto de las comunicaciones y de la información. Las bibliotecas, los centros de información y documentación, han de ser los pioneros en su adaptación a estos nuevos tiempos si no quieren perder el papel que deben jugar en el desarrollo humano: en estos momentos las nuevas tecnologías están estableciendo nuevos horizontes para todos los servicios bibliotecarios.

Hay que ser conscientes de que Internet está ofreciéndonos un mundo de oportunidades que no podemos desaprovechar. Sin embargo este nuevo mundo no está exento de problemas. Quizás el más frustrante sea la saturación de información que encontramos en Internet así como su falta de organización. Todo ello nos lleva a la desorientación en la propia navegación, que algunos autores definen como desbordamiento cognitivol.

Son sin duda las bibliotecas y centros de documentación, los que deben tomar el protagonismo de la organización de esa nueva información. Y un paso más en el desarrollo del papel que nos ha tocado jugar, lo suponen las llamadas bibliotecas virtuales, de las que cada vez se habla más, pero de las que nadie sabe bien de qué se trata. Estas bibliotecas digitales, ison solo complementos a las bibliotecas tradicionales, a las bibliotecas físicas que todos conocemos?, ise trata de proyectos aislados de digitalización de colecciones o la oferta de servicios en línea?

Sin duda que si no estuviésemos metidos en ajustes presupuestarios, muchos de estos proyectos serían hoy realidad, porque iquien se resiste a ofrecer servicios las 24 horas del día, ofrecerlos a dos minutos de la casa (el tiempo que se tarda en conectarse a Internet), aunque el bibliotecario se encuentre a miles de $\mathrm{Km}$ ?

\section{I.2. La revolución de las nuevas tecnologías}

No pretendemos hacer un estudio detallado de la revolución experimentada por las nuevas tecnologías en los últimos cincuenta años, aunque sí resaltar el papel desempeñado por algunos visionarios como Vannevar Bush, en la década de los cuarenta, con su sistema Memex (la primera máquina con enlaces ya en 1945), que puso las bases conceptuales de lo que después se llamaría el hipertexto, estando hoy presente con cada avance en tecnologías de la información.

Podemos decir que la informática se introduce en las bibliotecas en torno a los años setenta, para continuar 
con la llegada de los ordenadores, la automatización de las bibliotecas y las bases de datos bibliográficas online. De nuevo aparece el concepto de hipertexto cuando aparecen las grandes redes como Internet. Este concepto se desarrolla de nuevo para la creación de bibliotecas de información digital.

\section{3. ¿Qué entendemos por biblioteca digital?}

Actualmente reciben el nombre de bibliotecas digitales simplemente la selección de recursos en Internet que responden a la misma temática o una serie de documentos electrónicos accesibles a través de la web. El término "bibliotecas digitales" resulta atractivo frente al concepto arcaico de biblioteca física. Pero esto no es una biblioteca digital, o al menos no en el sentido que debemos darle los bibliotecarios.

Si una biblioteca es un espacio en el que se recoge y gestiona el uso de un fondo documental, una biblioteca virtual debe ser el espacio "virtual" (la información se almacena en el disco duro o en varios ordenadores), en el que existan documentos por propia definición digitales. $Y$ estos documentos deben estar seleccionados y organizados como en cualquier clase de biblioteca.

Un ejemplo de lo que para los bibliotecarios y profesionales de la información implica la idea de biblioteca digital, lo ilustran las siguientes instituciones cuando se refieren a sus programas de bibliotecas digitales:

La British Library Research and Innovation Center ${ }^{2}$ presenta su programa de biblioteca virtual con estas palabras: "La expresión biblioteca digital es un término ampliamente aceptado para describir las tecnologías digitales para la adquisición, almacenamiento, conservación y garantía de acceso a la información y material publicado originalmente en formato electrónico o digitalizado desde un formato impreso, audiovisual o cualquier otro".

La University of California Digital Library, nos ofrece un auténtico decálogo de la biblioteca digital en su informe "A framework for planning and strategic initiatives"3: Se nos demanda que ofrezcamos una biblioteca basada en nuevas tecnologías, con un acceso automático a los recursos de información, acceso fácil e inmediato a la información, bases de datos bibliográficas y documentales, y documentos en texto completo (documentos primarios), para todo el mundo, cuyo acceso se efectúa desde cualquier parte del mundo y por cualquiera.

Estos materiales digitales oscilan entre versiones electrónicas de publicaciones periódicas y monografías ofertados por los tradicionales editores, hasta manuscritos, fotografías, mapas, registros sonoros, y material similar digitalizado procedentes de las propias colecciones especiales de las bibliotecas o de novedades académicas electrónicas y bases de datos científicas desarrolladas por la colaboración de investigadores, informáticos, científicos de la información y bibliotecarios.

\subsection{Términos que se usan para el mismo concepto}

Diferentes términos se han utilizado para describir este concepto de biblioteca digital. Entre ellos nos encontramos Biblioteca virtual, Biblioteca digitalizada, Biblioteca electrónica, Biblioteca sin paredes ${ }^{4}$-cuyas colecciones y servicios son accesibles a través de la red y compartidos con los usuarios y otros servicios-, Biblioteca sin papeles, y más recientemente, Biblioteca Digital.

Y aún hoy nos encontramos con un término más, que recientemente ha hecho su aparición: La Biblioteca Híbrida. La biblioteca híbrida se refiere a la integración de los servicios de la biblioteca digital en los servicios tradicionales. Son aquellos proyectos que integran la tecnología bibliotecaria electrónica, dentro de la biblioteca tradicional. Se habla de biblioteca híbrida cuando se soportan diferentes recursos juntos en el contexto de trabajo de una biblioteca y se investiga y desarrollan sistemas y servicios integrados en entornos electrónicos e impresos.

El nombre de biblioteca híbrida refleja el estado de transición de las bibliotecas, que no son ni completamente impresas ni completamente digitales. La biblioteca híbrida intenta usar las tecnologías disponibles para hacer aquello que refleje lo mejor de ambos mundos. Esta iniciativa lleva a plantear una situación que está ocurriendo en nuestras bibliotecas: existencia de recursos de información con variados formatos, una gran variedad de interfaces incompatibles entre sí a través de las que el usuario debe encontrar la información.

Algunos de los programas de bibliotecas híbridas que se están llevando a cabo en todo el mundo son:

- Agora http://hosted.ukoln.ac.uk/agora

- Builder http://builder.bham.ac.uk

- Headline http://www.lse.ac.uk/blpes/headline.shtml

- HYLIFE http://www.unn.ac.uk/ ×xu2/hylife/

- MALIBU (gestión, humanidades)

http://www.kcl.ac.uk/humanities/cch/malibu/

\section{I.5. Los proyectos}

Como la mayoría de las nuevas aplicaciones en biblioteconomía con gran componente tecnológico, los primeros proyectos de bibliotecas digitales tienen su origen en las bibliotecas norteamericanas e inglesas.

En los comienzos de los años 90 se inicia un proceso de investigación y desarrollo de sistemas de almacenamiento, recuperación y difusión de información más completos e integradores que las bases de datos existentes hasta el momento. En sus inicios se desarrollaron sistemas propios, potentes y ágiles, para el acceso y la gestión de los documentos electrónicos (textuales y gráficos), pero con el éxito de la web, todas las investigaciones realizadas hasta el momento, van a considerarlo como única interfaz. 
Existe hoy día un reconocimiento internacional y nacional de que la biblioteca digital será la clave del área de investigación y desarrollo de las próximas décadas, y serán parte esencial de la infraestructura de la información que dará soporte a la investigación y la comunidad educativa.

Los objetivos de estos proyectos son:

- avanzar en lo que significa recoger, almacenar y organizar la información en formato digital y hacerla accesible para la investigación, recuperación y procesamiento a través de redes amigables;

- desarrollo de herramientas y tecnologías necesarias para acceder a esta gran cantidad de información;

- establecer colaboraciones con Instituciones para investigar en estos campos.

Los pasos que se están dando para la materialización de la biblioteca digital son:

- Conceptualizar una variedad de modelos para construir y acceder a redes de recursos de información y servicios.

- Elaborar un proyecto que realice y testee este modelo.

- Rediseñar completamente los servicios de suministro de información.

- Desarrollar políticas y procedimientos para la adquisición de recursos de información en soporte digital.

- Generar recursos financieros que sustenten el proyecto y su desarrollo.

- Establecimiento de políticas estratégicas que traten de los recursos humanos, técnicos, financieros y organizacionales que son críticos para el desarrollo de la biblioteca digital.

Algunos de estos proyectos implicados en la construcción de la biblioteca digital son:

- Elib, Electronic Libraries Programme www.ukoln.ac.uk/services/elib

- ARPA, NASA y National Science Foundation soportan los seis mayores Proyectos de Investigación en Biblioteca Digital: Digital Libraries Initiative (fases I y 2).

- Library of Congress ha iniciado National Digital Library Project y National Digital Library Federation.

- También la Library of Congress participa como colaboradora con el Digital Library Iniciatives del National Science Foundation.

- The join Information Systems Commitee creó Electronic Libraries Programme en Reino Unido y Comisión Europea.

\section{I.6. La biblioteca digital}

Podemos afirmar que existe una gran confusión con respecto a esta frase:

En primer lugar la propia comunidad bibliotecaria ha usado diferentes nombres para definirla a lo largo de estos años. El más reciente es Biblioteca Digital, y también el más aceptado en conferencias, recursos on line, literatura profesional.

Otro factor que influye en la confusión es que las bibliotecas digitales son objeto de estudio de diferentes áreas de investigación; según la comunidad que investigue, así su definición de biblioteca digital. Se trata tan solo de diferentes aproximaciones al concepto de Biblioteca Digital. Así por ejemplo desde el punto de vista de la recuperación de la información, se identifica Biblioteca Digital con una gran base de datos; para quien trabaja en tecnologías hipertextuales, Biblioteca Digital es una aplicación particular de los métodos hipertextuales; para la biblioteconomía, es un paso más en la automatización de bibliotecas, que comenzó hace 25 años.

La Biblioteca Universitaria de Barcelona, en su Curso sobre la Biblioteca Electrónica la define de esta forma: "La biblioteca electrónica es pues la colección de documentos en soporte electrónico, seleccionados por la biblioteca y hechos accesibles a los usuarios".

De hecho, todas estas apreciaciones son tan solo diferentes aproximaciones que se añaden al desarrollo de las bibliotecas digitales.

El tercer factor que debemos tener en cuenta es el hecho de que existen muchas cosas en Internet a las que la gente llama Biblioteca Digital, y que no lo son:

- programas de software para los informáticos, accesibles por Internet,

- vendedores de bases de datos o suministradores de documentos comerciales,

- para grandes empresas las bibliotecas digitales son sus colecciones de documentos comerciales y su sistema de gestión de documentos, fundamentalmente desde un punto de vista comercial y empresarial.

Y por último, podríamos hacernos la siguiente pregunta: ¿Es el WEB una biblioteca digital? Según Clifford Lynch $^{6}$, no lo es. Internet no se creó para soportar una documentación organizada ni para la recuperación de la información, como hacen las bibliotecas.

Desde el punto de vista de los bibliotecarios, podemos considerar "bibliotecas digitales" a aquellas bibliotecas con los mismos propósitos, funciones y objetivos de las bibliotecas tradicionales - desarrollo de colecciones, análisis temáticos, creación de índices, provisión de acceso, trabajo de referencia, y preservación-. Reducir esta definición sólo a las colecciones digitales, es simplemente infravalorar el trabajo que los bibliotecarios 
deben hacer para desarrollar y organizar sus colecciones y ayudar a sus usuarios a encontrar la información.

Y en esta idea abundan las Instituciones que colaboran con proyectos de biblioteca digital: enfatizan las tareas tradicionales de las bibliotecas (selección, acceso y preservación), y su vocación de servicio a una comunidad particular.

Las bibliotecas digitales son organizaciones que suministran acceso a recursos, incluyendo un personal especializado, seleccionando, estructurando, ofreciendo acceso intelectual, interpretando, distribuyendo, preservando la integridad y asegurando la persistencia en el tiempo de colecciones digitales que preparan y facilitan su acceso para ser usadas por una comunidad definida o grupos de comunidades.

La propuesta de Biblioteca Digital pasa necesariamente por la existencia de documentos primarios a los que acceder. Otro problema diferente se plantea según el acceso sea libre o restringido. Biblioteca digital comprende el concepto de biblioteca digitalizada, cuyo eje es una colección de documentos originariamente en formato tradicional pero actualmente digitalizado con la ayuda de las nuevas tecnologías.

Observamos como cada vez se están digitalizando más colecciones: los primeros fondos digitalizados son los procedentes de la literatura clásica, ya que están exentos de copyright o se han obtenido licencias para su difusión. Este es el caso de la Biblioteca Virtual de la Universidad de Valencia.

Otros proyectos, ya realidades son el proyecto Gutemberg, que aspira a reunir para el año 200 I una gran biblioteca digital y gratuita, integrada por 10.000 libros exentos de copyright? ${ }^{7}$. Se trata de ediciones sencillas que solo incluyen textos, y se encuentran alojadas en diversos ordenadores ubicados en todos los países. El ritmo de crecimiento es de un libro al día, introducido por 700 voluntarios, que previamente han investigado sus condiciones de copyright, y una vez que este ha expirado, se incluye en el proyecto. La cifra actual es de más de 1.300 libros, la mayoría de ellos de autores ingleses. Otros Proyectos a recordar serían el Poyecto Gallica de la Bibliotheque de France, o Dioscórides de la Complutense de Madrid.

No obstante, la mayoría de los documentos a los que accedemos a través de Internet e integran nuestras bibliotecas digitales, son documentos en $\mathrm{html}$ ofrecidos por los propios autores personales o corporativos.

\section{I.6. I. Características}

Vamos a enumerar aquellas características que nos parecen más significativas:

- Son la cara digital de las bibliotecas tradicionales, que incluyen tanto colecciones digitales como en otros soportes. Incluye por tanto soporte electrónico como papel.
- Incluye también los materiales que existen fuera de los límites físicos de la propia biblioteca.

- Idealmente suministra una visión integrada de toda la información que contiene dentro de la biblioteca sin importar su forma o formato. El acceso a esta información se realiza de forma integrada: Integración del OPAC y las BBDD de elaboración propia con las publicaciones electrónicas contratadas.

- Puede servir a comunidades particulares como lo hace actualmente una biblioteca, pero cuyos usuarios se encuentran completamente dispersos y acceden a ella a través de la red.

- La biblioteca digital requiere la colaboración de bibliotecarios e informáticos.

Sin embargo es imposible que hoy por hoy una biblioteca sea completamente digital, que suministre acceso instantáneo a todos los recursos, a todos los sectores de la sociedad, desde cualquier parte del mundo.

Para los bibliotecarios esta es la definición más completa porque potencia la biblioteca tradicional, preserva el trabajo que ellas hacen al mismo tiempo que integran las nuevas tecnologías, los nuevos procesos y medios.

\subsubsection{Elementos y retos}

Crear una biblioteca digital plantea serios retos. Integrar los nuevos medios digitales dentro de los tradicionales no es tarea sencilla debido a la propia naturaleza de la información digital, así como de sus predecesores (videos, cintas de audio, etc), cuya materialidad es menos fija, son fácilmente copiados y accesibles remotamente por múltiples usuarios de forma simultánea. Los elementos que vamos a considerar son:

- La arquitectura técnica (Los sistemas): el primer problema se plantea al constatar que la arquitectura técnica subyace tras cualquier proyecto de Biblioteca Digital. Las bibliotecas tendrán que acomodar su actual arquitectura técnica a los materiales digitales, enfatizando y priorizando el soporte técnico. La arquitectura debe incluir los siguientes componentes:

- Redes locales de alta velocidad y rápidas conexiones a Internet.

- Bases de datos relacionales que soporten diferentes formatos digitales.

- Motores de búsqueda de textos completos para indizar y suministrar acceso a los recursos.

- Variedad de servidores.

- Funciones de gestión de documentos electrónicos que ayuden a la gestión completa de los recursos electrónicos.

- Se trata de un sistema distribuido, no debe ser por tanto un sistema propietario, aunque aparezca como un único sistema de cara al usuario (transparente al usuario). Serán colecciones de diferentes sistemas y recursos, conectados a través de la red e integrados bajo una sola interfaz como la interfaz web o alguno de sus sucesores. 
Los recursos que debe soportar esta arquitectura pueden ser bases de datos tanto de materiales digitales como en papel, índices y herramientas de búsqueda, colección de punteros a Internet, fotografías, publicaciones periódicas electrónicas, datos numéricos, etc, y todos estos recursos pueden residir en diferentes sistemas y bases de datos pero aparece como un único sistema al usuario final.

Para llegar a la conexión total de todos los sistemas, un paso seria la constitución de redes, consorcios, que respeten normas y estándares comunes y que faciliten la interconexión.

- La formación de la colección digital. Existen tres métodos para construir la colección digital (Las colecciones):

- Digitalización.

- Adquisición de material ya digitalizado a editores.

- Acceso a recursos externos digitalizados almacenados en servidores Webs externos, otras bibliotecas, editores, etc.

Las colecciones digitales nos plantean en principio dos problemas: El control local de esas colecciones y la preservación y su acceso retrospectivo, lo que llamaríamos conservación electrónica tangible.

Dentro de las soluciones que se han barajado se proponen el acceso compartido a estas colecciones digitales, lo que llevaría al trabajo compartido de las instituciones. De esta forma se reducirían los costes y la redundancia de las colecciones, al mismo tiempo que propiciaría su coordinación, aumentando la riqueza de la colección que se ofrece.

- Los metadatos. Otro de los importantes problemas con los que nos planteamos es el de la identificación de estos documentos en un conjunto. Los metadatos es otro de los problemas centrales en la constitución de una biblioteca digital. Metadato es el dato que describe el contenido y los atributos de un particular ítem en una colección digital. Nos servimos por tanto de los metadatos para describir y representar los recursos digitales desde el punto de vista de la meta descripción o auto descripción. Se trata de una tarea habitual para los bibliotecarios: crear registros catalográficos que describan documentos. La vía más habitual es la utilización de etiquetas de tipo $<$ META $>$ (por meta tags) que se ubican en la sección $<$ HEAD $>$ de un documento HTML.

La norma Dublin Core es un solvente intento multidisciplinar e internacional de especificación de un conjunto estándar de meta datos que sirvan para identificar con mayor precisión el contenido de los documentos. De hecho a comienzos de 1999, la web oficial de la norma Dublin Core informaba de 42 instituciones científicas, culturales o académicas de todo el mundo que habían adoptado Dublin Core como estándar para describir sus recursos.

- Derechos de autor. En un entorno anglosajón se ha llegado a decir que la principal barrera al desarrollo de la Biblioteca Digital es el copyright. El concepto actual de copyright se rompe en un entorno digital en el que el control de las copias desaparece. Los recursos digitales son menos permanentes, de mas fácil reproducción, y remotamente accesibles por múltiples usuarios al mismo tiempo.

El problema de las bibliotecas es que no son dueñas de sus recursos como lo son editores y empresas comerciales, sino simplemente guardianes de esa información, no poseen el copyright de la información que guardan. Nunca podrán digitalizar libremente sus materiales ni transmitirlos legalmente, sino que deben desarrollar mecanismos que gestionen el copyright, que les permitan suministra información sin violar los derechos de autor.

Los problemas se plantean cuando entran en litigio por un lado la propia legislación sobre derechos de autor y los Derechos de los ciudadanos al libre acceso a la información.

Dos son las medidas necesarias a adoptar por la Comunidad Europea:

- Adaptar los derechos de autor y derechos afines a los nuevos desafíos tecnológicos y las oportunidades que comportan para lo que se precisa una protección jurídica armonizada con el objeto de crear condiciones equiparables de protección en todos los estados miembros, y

- Un desarrollo tecnológico de los sistemas que hagan posible la gestión y la protección electrónica de los derechos.

La primera medida se plasma en una Directiva, que otorga a los Estados Miembros cierta flexibilidad para aplicar y recoger estos principios en sus legislaciones. En primer lugar se trata de una medida de armonización, entre los países miembros de la Unión, unos seguidores de la tradición latina (derechos de autor) y otros de la anglosajona (copyright), existiendo por lo tanto una lucha económica detrás de los procedimientos jurídicos. Al considerar la Comunidad europea como un mercado único, se imponen medidas que eviten los obstáculos a la libre circulación de bienes y servicios.

Las Directivas adoptadas hasta ahora, han dado a la industria cada vez más protección en relación con el acceso a la información electrónica.

El segundo punto entra de lleno en la implantación de sistemas que gestionen el copyright, en base a un sistema universal de identificación, los Copyright Management information (CMI), o mejor, Rights Management Information, pues también puede afectar a otros derechos relacionados. Cualquier objeto que pueda ser digitalizado y visto en un ordenador, puede llevar codificado un CMI. Gracias a él, el usuario puede hacer un uso autorizado de un trabajo con copyright.

En diciembre de 1997, la Comisión europea elevó una propuesta de Directiva sobre Derechos de autor y transmisión electrónica de documentos. Esta 
propuesta ha recibido reacciones en contra de todos los profesionales relacionados con el acceso a la información.

Se advierte en la Propuesta que nada podrá ser visualizado, leído, usado o copiado sin autorización o pago adicional. Esto da un paso atrás si lo relacionamos con lo que actualmente ofrecen las bibliotecas, centros de documentación, archivos, museos, etc.

En el contexto en el que nos movemos, es necesario un diálogo entre las partes afectadas para que no se creen barreras infranqueables entre ricos y pobres en información. Y este proyecto de Directiva implica en sí mismo un bloqueo total al acceso, pues solo obedece a una exigencia de rentabilidad inmediata.

Por otro lado, las bibliotecas no son saqueadoras de la propiedad intelectual, y en sus reglamentos se prohibe todo uso comercial indebido. Por lo tanto, deben reconocerse aquellas excepciones que permitan a las bibliotecas cumplir con su misión de información a los ciudadanos y de conservación del patrimonio intelectual. Es completamente esencial para el futuro.

\subsubsection{Transformación de las funciones}

La primera transformación la observamos en la propia definición de biblioteca: cambia la idea de biblioteca estática por biblioteca distribuida o virtual. Los nuevos recursos de información no estarán bajo el control físico del bibliotecario. Los usuarios tendrán otras necesidades: una batería de terminales de ordenador en vez de una tradicional sala de lectura. Si las publicaciones electrónicas aumentan, el espacio físico tenderá a disminuir mientras que aumentará la necesidad de almacenamiento electrónico.

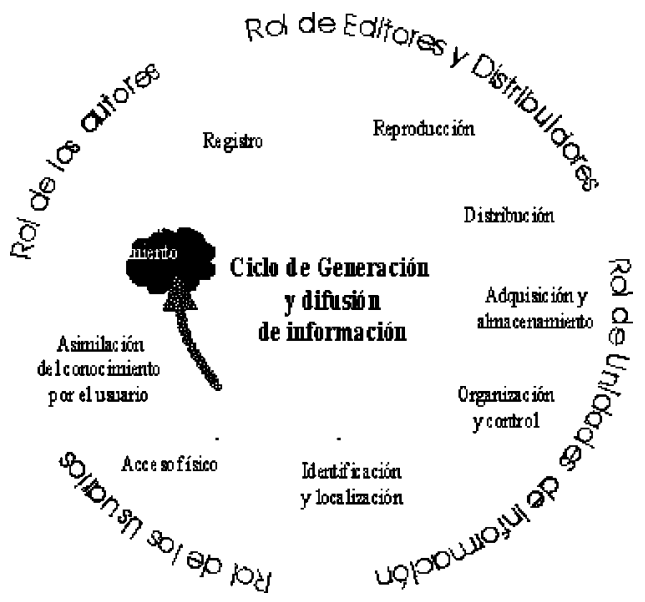

Los usuarios que buscan información, lo harán más por si mismos, sin requerir los servicios de un intermediario. El bibliotecario podría servir de apoyo al aprendizaje sobre las redes.
Las Instituciones, las Universidades entre ellas, tendrán que hacer frente al imperativo económico de maximizar los resultados mediante la gestión de ingresos y derechos, sobre los recursos de investigación de los que son propietarios (tesis doctorales, trabajos de investigación).

En resumen podemos considerar como pilares de la Biblioteca Digital, los siguientes puntos aportados por la Comisión Europea, en su Programa temático de tecnologías de la Sociedad de la Información:

- Mejorar y expandir los servicios a los usuarios, proporcionando un acceso unificado e integrado a recursos distribuidos y diferentes.

- Acceso a recursos distribuidos con la invención de interfaces, arquitectura de sistemas y normas relacionadas.

- Integración de lo real con lo virtual, de lo físico con lo lógico, de lo impreso con lo digital. (Biblioteca hibrida).

- Necesidad de gestionar el cambio y la transición de las formas tradicionales a lo digital y multimedia.

- Continuidad del acceso y garantía de la disponibilidad a largo plazo del contenido creado hoy. (Preservación y conservación). Preservación digital del patrimonio cultural.

- Desarrollo sostenido de infraestructuras para la gestión del acceso y los servicios, y para mantener los recursos.

\section{APROXIMACIÓN A LA BIBLIOTECA DIGITAL DEL PATRIMONIO HISTÓRICO}

De acuerdo con el concepto, características y elementos constitutivos de la Biblioteca Digital, se plantea una propuesta para la creación y desarrollo de la Biblioteca Digital del Patrimonio Histórico.

\section{I. Planificación}

En primer término, se considera vital abordar la planificación y diseño del proyecto, con el fin de reducir costes inútiles y pasos en el vacío, de acuerdo con las siguientes premisas:

- Determinación de los objetivos y límites del proyecto: integrar y facilitar a los usuarios el acceso a los recursos y servicios de información sobre patrimonio histórico, desarrollados y recopilados por el Centro de Documentación del Instituto Andaluz del Patrimonio Histórico (IAPH).

- Determinación de los criterios de calidad: disponibilidad del sistema en el plazo mínimo de un año, con la información completa y actualizada de los bienes 
culturales andaluces y otras fuentes de información sobre el patrimonio histórico, con una periodicidad de actualización mensual.

- Análisis de la demanda y de la competencia: de acuerdo con el estudio del marco legal y funcional y de los usuarios reales y potenciales, se determina el vacío existente en la oferta de productos y servicios de información relativos al patrimonio histórico y a los bienes culturales andaluces, así como la amplia demanda de investigadores, administración y público en general.

- Análisis de especificaciones y recursos: se establece la necesidad de una fuerte asignación económica inicial para la dotación de infraestructura técnica, recursos informativos y recursos humanos necesarios (informáticos y documentalistas), así como inclusión de una partida presupuestaria anual para la ampliación y mantenimiento del sistema en general.

- Análisis de funciones y tareas, determinación de plazos y asignación de recursos: formación del equipo de trabajo, distribución de tareas, establecimiento de prioridades, faseado y calendario, etc.

- Coordinación con otros proyectos coincidentes, con el fin de evitar duplicaciones de trabajo y compartir recursos.

- Diseño de la estructura jerárquica de los contenidos y de los lazos asociativos, que se muestra en la propuesta de diseño.

- Diseño de los procedimientos de acceso: índices jerárquicos textuales y visuales, índices alfabéticos, búsquedas por palabras claves, inclusión de descriptores en los metadatos de las páginas.

- Diseño del interfaz del usuario: formularios, maquetación, diseño de plantillas, etc.

\subsection{Propuesta}

De forma previa a la realización de la propuesta de la biblioteca digital del patrimonio histórico, se ha procedido al análisis de varios modelos, que representan, en orden creciente, tres aproximaciones a la biblioteca digital:

- Biblioteca Virtual de la Universidad Oberta de Catalunya http://www.uoc.es/

- Biblioteca de la Universidad Complutense de Madrid http://www.ucm.es/BUCM/

- Biblioteca Virtual, elaborada por Greendata http://www.greendata.com/pqdbv/

De acuerdo con los planteamientos teóricos expuestos y las ejemplificaciones dadas por los modelos analizados, se establece una aproximación de la estructura jerárquica y asociativa de la página web de la biblioteca digital del patrimonio histórico.
El desarrollo de la Biblioteca Digital del Patrimonio Histórico se concibe como un punto informativo accesible desde la página principal del servidor web del IAPH. A través del enlace Biblioteca Digital se presenta en una página índice la estructura general de los contenidos, con los apartados principales y explicación de sus contenidos básicos:

- Logotipo.

- Información General: ofrece los datos básicos sobre los objetivos, proyectos, actividades, estructura orgánica, áreas funcionales, servicios y productos de información, fondos, temáticas, normativas de uso, horarios, formas de acceso, plano de situación, preguntas más frecuentes (FAQs) y recursos humanos de la biblioteca digital del patrimonio histórico.

- Catálogos/Bases de Datos: integra los catálogos y bases de datos del y sobre el patrimonio histórico, producidos desde la biblioteca digital del patrimonio histórico y/o accesibles a través de Internet, contratados o de acceso público.

- Sala de Lectura: contiene una selección de publicaciones a texto completo y de sumarios de revistas, procedentes del fondo propio, y de otras publicaciones de acceso remoto, accesibles mediante suscripción o gratuitas.

- Sala de Prensa: ofrece el acceso a los medios de comunicación y boletines de noticias existentes en la web, así como a los boletines de noticias disponibles en el fondo.

- Sala de Imágenes: permite la consulta del banco de imágenes del patrimonio histórico andaluz, y de otros fondos gráficos de interés existentes en el Web, de acceso público o restringido.

- Servicio de Difusión Selectiva de la Información: se establecen perfiles específicos y personalizados de búsquedas, accesibles a través de claves personales.

- Salas Temáticas: presenta el acceso integrado a los recursos de información, internos y externos, estructurados en ámbitos temáticos.

- Búsquedas: permite las búsquedas en los contenidos de la página web, a través de un motor de búsqueda interno.

- Buzón de sugerencias/consultas: se establece un canal de comunicación fluido y rápido para la atención de las opiniones, sugerencias y consultas de los usuarios virtuales.

- Encuesta de satisfacción de usuarios: con el fin establecer mecanismos de retroalimentación de los servicios que se ofrecen, los usuarios disponen de una encuesta en línea para expresar el nivel de satisfacción alcanzado, que se activará de forma automática al final de cada sesión.

- Índice: presenta la estructura completa de la página web.

- IAPH: acceso directo a la página principal del Instituto Andaluz del Patrimonio Histórico. 
- Idiomas: castellano / inglés, que permite la selección de idioma de consulta.

- E-mail. URL. Fecha de la última actualización de la información.

A partir de esta estructura general se puede iniciar la navegación vertical por cada apartado principal, que presenta en una página-sumario la estructura específica del apartado correspondiente, con los subapartados y la explicación de sus contenidos básicos. Sin embargo, con el fin de facilitar la navegación horizontal se mantiene en todas las páginas un frame con la estructura general reseñada.

\section{I) Información General}

- Presentación: dependencia, fecha de creación, breve historia, misión, espacios, etc.

- Estructura: departamentos, áreas, unidades de información.

- Líneas estratégicas: objetivos-proyectos-actuaciones, memorias de actividades.

- Fondos: tipologías, volumen, temáticas, procedencia, cronología, formación, organización, etc.

- Servicios: información general y normativas de los servicios de consulta, préstamo, reproducción, préstamo interbibliotecario y fotodocumentación, adquisiciones, información, difusión selectiva de la información, y formación de usuarios. Asimismo, se ofrecen los formularios de los servicios en línea.

- Productos: descripción de las bases de datos internas y catálogos de los fondos, catálogo de bases de datos en $\mathrm{Cd}$-Rom, boletines bibliográficos, dossiers temáticos, etc.

- FAQs: preguntas más frecuentes acerca de la Biblioteca Digital del Patrimonio Histórico.

- Recursos Humanos: directorio del personal, nombre completo, dependencia, teléfono, e-mail.

- Directorio: dirección postal, teléfonos, correo electrónico, fax, y plano de situación territorial e institucional.

- Registro de usuarios: información sobre la tipología de usuarios y niveles de acceso, y formulario para la identificación y establecimiento de códigos de acceso para los usuarios.

El desarrollo, actualización y mantenimiento de la información general será responsabilidad de la dirección de la biblioteca digital, con un plazo de actualización anual, debido al carácter permanente, excepto para algunas modificaciones puntuales. Por otro lado, las peticiones de los servicios en línea se redireccionan de forma automática a los responsables de los servicios correspondientes; y el registro de los usuarios se gestionará por el administrador del sistema.

\section{2) Catálogos/Bases de Datos}

- Catálogos de la biblioteca digital del patrimonio histórico, accesibles vía web:

- Catálogo general.

- Catálogo de Publicaciones Periódicas.

- Boletines de Adquisiciones.

Se contempla, además, la vinculación de las referencias bibliográficas con la consulta del texto completo, en su caso, disponibles en la sala de lectura, y viceversa.

- Otros Catálogos: relación de enlace a catálogos de interés de otras instituciones.

- Bases de Datos de los Bienes Culturales de Andalucía: patrimonio arquitectónico, arqueológico, etnológico, mueble, actividades de gestión cultural, e intervenciones.

- Bases de Datos de Patrimonio Histórico, desarrolladas por otros organismos e instituciones y disponibles en el Web.

- Bases de Datos de Fuentes de Información del Patrimonio Histórico de Andalucía: información bibliográfica y documental, directorios, noticias de prensa y legislación patrimonial.

- Bases de Datos de fuentes de información especializadas y multidisciplinares de interés para el patrimonio histórico, disponibles en Internet, contratadas o gratuitas.

En este apartado se ofrece la búsqueda integrada de todos estos recursos con una única pantalla de interrogación avanzada: operadores booleanos, truncamiento, delimitación por campos, e instrucciones para la consulta. Asimismo se facilita el acceso individualizado a cada uno de los recursos disponibles, mediante un listado alfabético y por materias, que incluye además un enlace a la siguiente información de cada recurso: descripción, productor, editor, actualización, idioma, tipo de acceso, materias.

De forma complementaria, se facilita el acceso a diversos formularios de los servicios en línea:

- Formulario de adquisiciones, para la solicitud de adquisición por los usuarios de aquéllas publicaciones no incluidas en el catálogo.

- Formulario para la obtención de documentos, para la petición de publicaciones presentes en los catálogos, propios y externos y no disponibles en formato digital.

- Formulario de demandas puntuales, para la obtención de una información más exhaustiva sobre el patrimonio histórico andaluz. 
- Formulario de suscripción al boletín de adquisiciones, para su envío periódico a través de una lista de distribución.

Las informaciones contenidas en los catálogos y bases de datos internas se encuentran en constante actualización, por lo que el plazo de actualización será mensual, siendo responsabilidad de cada una de las áreas de desarrollo sectorial, en colaboración con un informático del equipo coordinador de la página web. Por el contrario, la actualización e incorporación de los enlaces a recursos externos será una labor continua de un documentalista del servicio de información y referencia.

\section{3) Sala de Lectura}

- Hemeroteca, que contiene una selección de revistas a texto completo y sumarios de revistas, procedentes del fondo propio, y de otras publicaciones de acceso remoto, accesibles mediante suscripción o gratuitas.

De forma complementaria se ofrece el formulario de suscripción a los boletines de sumarios de la biblioteca, para el envío periódico a los usuarios de los sumarios de las revistas previamente seleccionadas, a través de una lista de distribución (hacer llegar la información al usuario o efecto "push"). Además, se establece la relación entre el catálogo de publicaciones periódicas y los sumarios de la revista correspondiente, y viceversa.

La disponibilidad actual a texto completo de toda la colección resulta, sin embargo, difícil, ya que supone el escaneado de un gran volumen de información y los problemas derivados de los derechos de autor. Sin embargo, se incorporarían aquéllas publicaciones a texto completo no sujetas al copyright, producidas por el IAPH, y/o disponibles en el web: monografías, obras de referencia (diccionarios, enciclopedias, anuarios, tesauros, directorios...), literatura gris, etc.

La responsabilidad de la digitalización de las publicaciones propias es del área de técnicas gráficas, previa selección del responsable de la sala de lectura, y de acuerdo con un calendario faseado de nuevas incorporaciones para la actualización de la información. Respecto a los enlaces con recursos externos, se actualizarán de forma continúa por un documentalista de la sala de lectura.

\section{4) Sala de Prensa}

- Quiosco de Prensa: enlace a los principales periódicos, agencias, etc. disponibles en el Web.

- Boletines de Noticias: disponibilidad de los boletines existentes en el fondo y/o de acceso remoto, a texto completo.

La selección, actualización y mantenimiento de esta información corresponde al documentalista responsable de la sala de prensa, encargado de la localización, selección y organización de los enlaces externos, y de la selección de los boletines disponibles en el fondo para su digitalización. El plazo de actualización sigue las mismas pautas que la sala de lectura.

\section{5) Sala de Imágenes}

- Banco de Imágenes del Patrimonio Histórico Andaluz: ofrece la posibilidad de poner a disposición de los usuarios cualquier imagen localizada en la base de datos del fondo gráfico, a través de un formulario avanzado de recuperación de la información. Este servicio es fundamental en la temática del patrimonio histórico: arquitectura, arte, museos, etc.

- Imágenes del patrimonio histórico: enlace a otros recursos gráficos existentes en la Web que contengan el acceso a las imágenes relativas al patrimonio, de acceso público o mediante pago.

La elaboración y digitalización de las imágenes es responsabilidad de un técnico en técnicas gráficas, previo encargo de los coordinadores de las bases de datos de los bienes culturales andaluces, que se realiza en campañas semestrales. De forma paralela, se procede a la actualización de la información referencial contenida en la base de datos gráfica por un documentalista. Respecto a las imágenes propias se establece un plazo de actualización semestral, mientras que la localización y mantenimiento de los enlaces a recursos externos se realiza de forma continúa por un documentalista del fondo gráfico.

\section{6) Servicio de Difusión Selectiva de la Información}

Se establecen perfiles de forma automática, a través de las búsquedas realizadas por los usuarios en las consultas a las bases de datos/catálogos. El sistema capta el perfil y pregunta al usuario si quiere guardar esa búsqueda, que en caso afirmativo, el sistema actualizará de forma periódica con la nueva información que se incorpore. Con ello, se crean acervos informativos específicos y personalizados, accesibles a través de claves personales de los usuarios suscritos.

Asimismo, los perfiles de mayor interés que cubran necesidades de información colectivas se incluirán en las salas temáticas correspondientes, de forma que pueda ser utilizada por todos los usuarios especializados en dicho ámbito.

\section{7) Salas Temáticas}

Tiene como objetivo la presentación y acceso integrado a los recursos de información, internos y externos, estructurados en ámbitos temáticos. Cada apartado se subdivide en diferentes subapartados temáticos especializados, de acuerdo con las especialidades de cada ámbito, y los recursos de información disponibles.

- Antropología/Etnología: guías y directorios de antropología, instituciones académicas, centros de investigación, 
organizaciones profesionales, museos, bibliotecas, centros de documentación, catálogos, bases de datos, revistas, otras publicaciones, listas de distribución, dossiers temáticos, bienes de interés etnológico...

- Arqueología: guías y directorios de arqueología, instituciones académicas, centros de investigación, proyectos, organizaciones profesionales, museos, yacimientos arqueológicos, conjuntos arqueológicos, bibliotecas, centros de documentación, catálogos, bases de datos, revistas, otras publicaciones, empresas, listas de distribución, sistemas de información geográfica, arqueología subacuática...

- Arquitectura: directorios y guías de arquitectura, organizaciones profesionales, bibliotecas, centros de documentación e información, bases de datos, catálogos, revistas, otras publicaciones, instituciones académicas, centros de investigación, otros organismos oficiales, servicios profesionales, sector privado, arquitectos, edificios, conjuntos históricos, catedrales, jardines históricos, intervenciones, listas de distribución.

- Arte/ $/ H^{a}$ del Arte: guías y directorios de arte, instituciones académicas, centros de investigación, museos, fundaciones, asociaciones, galerías, ferias, exposiciones, anticuarios, bibliotecas, catálogos, centros de documentación e información, bases de datos, revistas, otras publicaciones, listas de distribución, artistas, catálogos de bienes artísticos, restauraciones, dossiers temáticos geográficos y/o tipológicos, itinerarios culturales...

- Biblioteconomía y Documentación: índices, guías y directorios especializados, instituciones académicas y de investigación, organizaciones profesionales, otros organismos oficiales, sector comercial (empresas, distribuidores, editoriales, librerías), bibliotecas, centros de documentación e información, catálogos de bibliotecas, bases de datos, publicaciones electrónicas, listas de distribución...

- Conservación/Restauración: guías y directorios de conservación y restauración, organismos oficiales, centros de investigación, asociaciones profesionales, instituciones académicas, empresas, memorias de intervención, proyectos de restauración, informes diagnóstico, técnicas aplicadas, intervenciones arqueológicas, bases de datos, bibliotecas, revistas, centros de información, intervenciones experimentales, métodos de análisis, ...

- Formación del PH: agenda de cursos de posgrado y de especialización del IAPH, cursos de posgrado de patrimonio en España, jornadas y cursos en España y en el extranjero, instituciones académicas, otros organismos de formación, aulas virtuales, cursos de formación de Bienes Culturales...

- Internet: buscadores de información, metabuscadores, listas de correo, grupos de noticias, recursos gratuitos, información sobre la red, programas...
- Legislación del PH: guías y directorios de legislación, boletines oficiales de Andalucía, autonómicos, nacional y europeos, disposiciones y textos legales a texto completo, régimen jurídico del patrimonio histórico andaluz, organismos oficiales, revistas...

- Museos/Museología: directorios de museos, museos agrupados por tipologías, organizaciones profesionales, organismos públicos, bibliotecas y centros de documentación, bases de datos, catálogos, revistas, colecciones de museos, visitas virtuales.

- Organismos públicos: nacionales, autonómicos, provinciales, municipales, internacionales, revistas, documentos oficiales...

La localización, selección, organización y actualización de estos apartados constituye una labor continua de un documentalista del equipo coordinador de la página web. Para el faseado de esta ingente labor, pero por otro lado indispensable, se establece una actualización mensual para cada una de las salas, consistente en la selección y adecuación temática de los recursos propios y de los enlaces externos, así como en la redacción de propuestas para la elaboración de nuevos productos especializados de información.

\section{CONCLUSIONES}

El diseño de la biblioteca digital del patrimonio histórico está planteada desde un enfoque teórico, ya que las posibilidades potenciales del servidor web del Instituto Andaluz del Patrimonio Histórico se encuentra, hoy por hoy, simplemente dibujadas. El desarrollo de líneas de futuro suponen, sin lugar a dudas, la consecución de importantes logros, encaminados a facilitar el acceso rápido y fácil de los usuarios a los productos y servicios de información disponibles, aportando además la integración con otros recursos de interés existentes en Internet.

Con ello, estaríamos en la línea de lo que se ha denominado como biblioteca híbrida. Pero, es necesario que establezcamos una nueva orientación de nuestras actuaciones a medio plazo, es decir, reconvertir los productos y servicios para la creación de una auténtica biblioteca digital del patrimonio histórico.

En conclusión, la biblioteca digital es todavía una posibilidad abierta, cuyo potencial está por desarrollar. Pero debemos trabajar en el campo de la propuesta y la exploración con el fin de establecer alternativas, que ofrezcan los mejores medios para el aprovechamiento de los recursos de nuestro tiempo, manteniendo la misma filosofía de fondo, facilitar el acceso a la información en el mayor grado posible. 
Bibliografía

Bibliotecas virtuales

http://www.vallesnet.org/ xavip/articles/bibvir3.htm

Digital Libraries: Definitions, Issues anda Challenges. UDT Occasional Papers. IFLA. \# 8

D-Lib Magazine http://mirrored.ukoln.ac.uk/lis-journal/dlib/

LAFUENTE LÓPEZ, R. La biblioteca digital. En Curso de Documentación Digital [en línea] http://camelot.upf.es/digital/aula.htm [consulta: |4/04/99].

LIMÓN RODRÍGUEZ, S., ORTEGA VAQUERO, I. El Servidor Web del Instituto Andaluz del Patrimonio Histórico. En Boletín PH, n¹9, junio 1997, p.139-146.

ORTEGA VAQUERO, I., LIMÓN RODRÍGUEZ, S. Internet como fuente y servicio de información del Patrimonio Histórico: la experiencia del Instituto Andaluz del Patrimonio Histórico (IAPH). En I Jornadas Andaluzas de Documentación, 1997, p. 323-329.

RUSBRIDGE, C. The electronic libraries programme: Hybrid libraries, clups and preservation. [en línea].

http://www.uklon.ac.uk/services/papers/b//b/ri078/content/report 15.html [consulta: 03/05/99].

TELLIER, S. Modele de development d'une bibliotheque virtuelle sur le Web. En Documentaction et bibliotheques, avril-juin, 1997.

Una biblioteca virtual. En Information world en español, $n^{\circ} 23$, 1994, p. I-2.
PROYECTOS

Biblioteca Popular en Internet http://www.arrakis.es/ margaix

British Library research and Innovation Center

http://portico.bl.uk/services/ric/diglib/extfaq.htm

Digital Library Initiatives http://www.cise.nsf.gov/iis/dli_home.html http://memory.loc.gov/ammem/dlib2/

Elib, Electronic Libraries Programme http://www.ukoln.ac.uk/services/elib

Greendata http://www.greendata.es/pqdbv

Internet Public Library http://www.ipl.org

Michigan Electronic Library http://mel.lib.us

University of California Digital Library. A framework for planning and strategic initiatives

http://sunsite.berkeley.edu/UCDL/summary.html

\section{Notas}

\footnotetext{
I. Rovira, C. (1997). "Entornos hipertextuales de aprendizaje". En P. Cid; J. Baró (eds). Anuari Socadi de Documentació. Barcelona: Societat catalana de Documentació.

2. http://portico.bl.uk/services/ric/diglib/extfaq.htm

3. http://sunsite.berkeley.edu/UCDL/summary.html
}

4. Definición de Tellier Sylvie. Véase la bibliografía. 